\title{
The relationship between COPD Assessment Test (CAT) scores and Distress Thermometer (DT) results in COPD patients
}

\author{
Marcelina Makuch ${ }^{1, B-D \oplus}$, Joanna Milanowska ${ }^{2, A, C-D \oplus}$, Marek Michnar, ${ }^{1, B \oplus}$, Marcin Makuch ${ }^{3, C \odot}$, \\ Marzena Samardakiewicz ${ }^{2, \mathrm{E}-\mathrm{F}}{ }^{\oplus}$, Janusz Milanowski ${ }^{1, \mathrm{E}-\mathrm{F}}$ ( \\ ${ }^{1}$ Department of Pulmonology, Oncology and Allergology, Medical University, Lublin, Poland \\ 2 Department of Applied Psychology, Chair of Psychology, Medical University, Lublin, Poland \\ ${ }^{3}$ Department of Internal Medicine, Medical University, Lublin, Poland \\ A - Research concept and design, B - Collection and/or assembly of data, C - Data analysis and interpretation, \\ $D$ - Writing the article, E-Critical revision of the article, F- Final approval of article
}

\begin{abstract}
Makuch M, Milanowska J, Michnar M, Makuch M, Samardakiewicz M, Milanowski J. The relationship between COPD Assessment Test (CAT) scores and Distress Thermometer (DT) results in COPD patients. Ann Agric Environ Med. 2020; 27(4): 689-694. doi: 10.26444/aaem/11410
\end{abstract}

\section{Abstract}

Introduction. Chronic Obstructive Pulmonary Disease (COPD) is a condition that affects over 2 million adults in Poland. In recent years, increasing attention has been focused on improving the quality of life of patients with COPD, which includes alleviating their physical discomfort and relates to their mental health. It is therefore critically important to evaluate research tools that can accurately assess the relationship between the physical and mental health of patients with this disease.

Objective. This aim of the study is to evaluate the relationship between the COPD Assessment Test (CAT) and the Distress Thermometer and Problem List results in COPD patients.

Materials and Method. The research evaluated 70 patients with COPD as defined by the Global Initiative for Chronic Obstructive Pulmonary Disease (GOLD) criteria. Demographic data was obtained at baseline. Disease-specific quality of life was assessed using the CAT score, while overall distress was determined using the Distress Thermometer (DT) scale and a modified Problem List. The relationship between the CAT scores and the results of the Distress Thermometer and Problem List was statistically compared. The study was approved by the Bioethics Committee, and all patients provided written informed consent.

Results. The mean \pm SD age was $69.6 \pm 9.05$ (range 47-90) years. The average distress level was 4.09 \pm 1.95 . A significant relationship was established between the CAT score and the results of the Distress Thermometer Scale $(p<0.001)$; patients with higher CAT scores showed the highest level of distress.

Conclusions. CAT was shown to be a simple, fast and clear measurement of disease-specific quality of life and was correlated with levels of distress in patients with COPD. Every patient with COPD should be evaluated using a scale such as the DT to measure their level of psychological distress.

\section{Key words}

COPD, COPD Assessment Test, Distress Thermometer and Problem List, distress

\section{INTRODUCTION}

Chronic obstructive pulmonary disease (COPD) is a common respiratory disease characterized by airflow limitation caused by exposure to noxious particles or gases. The most common symptoms include dyspnea, cough and sputum production. The most important risk factor for COPD is cigarette smoking. Other risk factors include environmental exposures (e.g. air pollution), genetic abnormalities or accelerated aging [1]. COPD often presents in combination with other morbidities; common concomitant chronic diseases include cardiovascular problems (e.g. hypertension, coronary heart disease, stroke), skeletal muscle disorders, diabetes mellitus, metabolic syndrome, osteoporosis, lung cancer, psychiatric illness (e.g. depression and anxiety) and cognitive dysfunction $[2,3]$. Contemporary research suggests that patients with COPD have a high rate of comorbid psychiatric disorders

Address for correspondence: Joanna Milanowska, Department of Applied Psychology, Medical University of Lublin, Poland

E-mail: joannamilanowska@umlub.pl

Received: 10.04.2019; accepted: 08.11.2019; first published: 12.12.2019 as well as nonspecific psychological disorders, which are important determinants of health outcomes and health care utilization in patients with COPD. The previously mentioned comorbidities also negatively impact the clinical condition of patients with COPD and worsen their prognosis [3].

Smoking cessation is key to influencing the natural history of COPD. The newest guidelines suggest utilizing common maintenance medications: short-acting beta2-agonists (SABA), long-acting beta2-agonists (LABA), short-acting anticholinergics (SAMA), long-acting anticholinergics (LAMA), combination SABA/SAMA, combination LABA/ LAMA, methylxanthines, combination LABA/corticosteroids in one device (ICS), triple combination LABA/LAMA/ICS, phosphodiesterase- 4 inhibitors, and mucolytic agents. The treatment plan should consider the full clinical picture of the patient [1].

The COPD Assessment Test (CAT) is a very popular scale for scoring health impairment status in COPD. Studies by Jones et al. confirmed that the CAT is a simple questionnaire for monitoring COPD with worldwide relevance [4].

In 1997, the National Comprehensive Cancer Network created the Distress Thermometer (DT) and Problem List 
(PL), as a screening scale for distress among oncological patients [5]. Grassi et al. certified the usefulness of DT among patients suffering from cancer [6]. DT, however, was not clinically tested among COPD patients.

\section{OBJECTIVES}

The prospective study aimed to evaluate the relationship between the results of the COPD Assessment Test (CAT) and the Distress Thermometer and Problem List in COPD patients. The initial hypothesis assumed that a correlation exists between the CAT score and score on the Distress Thermometer scale.

\section{MATERIALS AND METHOD}

The evaluation of a patient with COPD includes assessing the severity of the obstruction in pulmonary function tests, as well as determining the nature of the symptoms and risk of exacerbations. One of the methods for obtaining an objective assessment of the impact of COPD on everyday life is the COPD Assessment Test (CAT), an eight-item measure of health impairment status in COPD. The CAT is a simple and reliable instrument, and clinician can explore the results during their consultation. Despite the small number of component items, the CAT test covers a broad range of effects of COPD on patients' health. Jones et al. assessed that the utility of the CAT score among COPD patients was analyzed in three prospective international studies (Europe and the USA, $n=1.503$ ). Consequently, the COPD Assessment Test is extensively documented in the scientific literature and developed to be globally applicable (Fig. 1). The CAT was introduced into Polish medicine through the Global Initiative for Chronic Obstructive Lung Disease and was adapted by Paweł Śliwiński, Dorota Górecka, Ewa Jassem and Władysław Pierzchała (Polish Respiratory Society Guidelines for Chronic Obstructive Pulmonary Disease) $[1,7,10]$.

The CAT is freely available (although GlaxoSmithKline owns the copyright to protect it from unauthorized changes) for use in daily clinical practice (www.

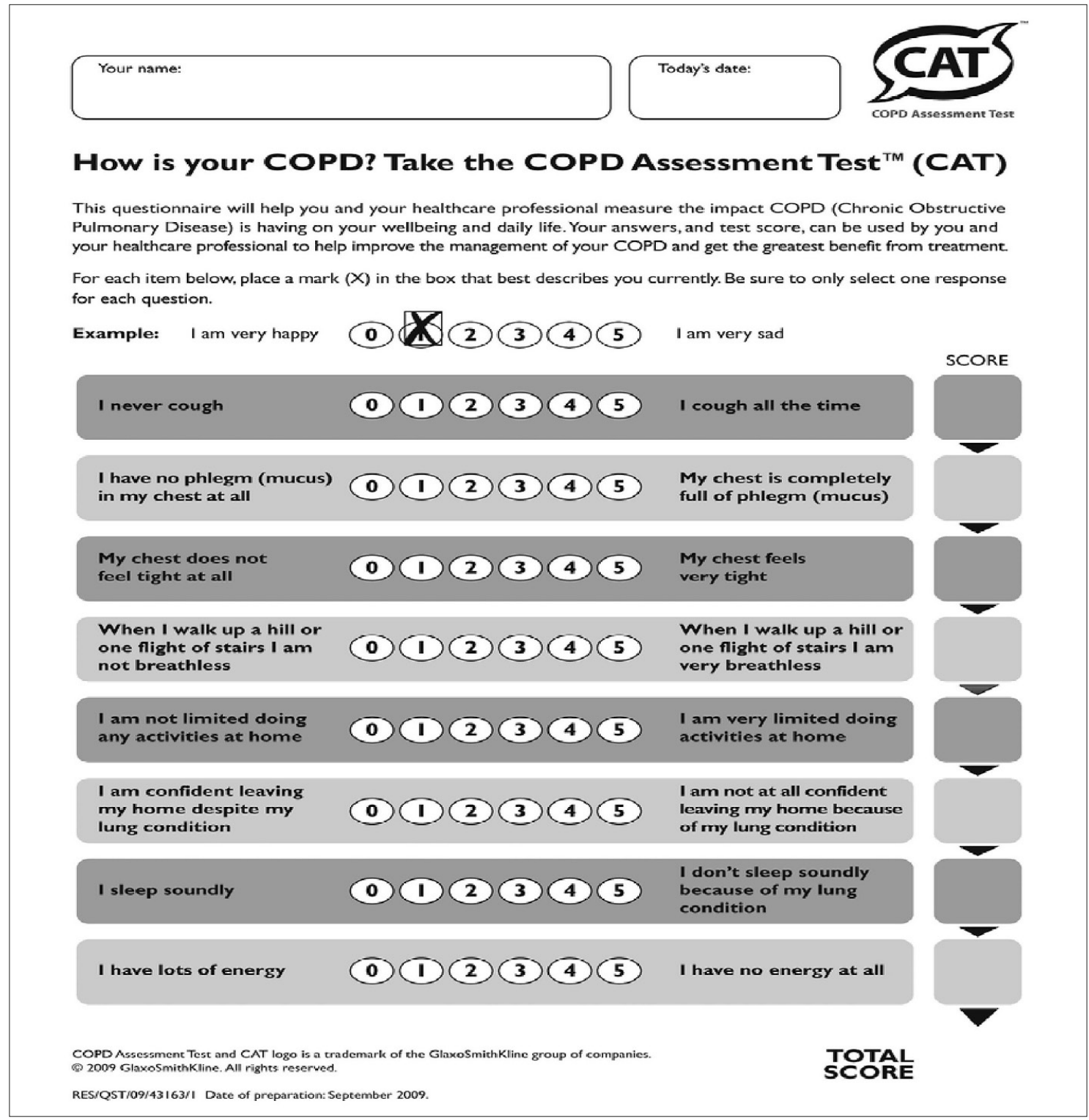

Figure 1. COPD Assessment Test (CAT) by GlaxoSmithKline, (2009) 
catestonline.org). Studies have shown that it is responsive to changes in the disease, treatment and rehabilitation $[7,8]$. The role of the CAT test is to supplement the information obtained from lung function tests and the assessment of exacerbation risk. The CAT test does not categorize patients into severity groups for the purpose of treatment [9]. The CAT has a scoring range of $0-40$ and correlates very closely with much more complex health status questionnaires, such as the St. George's Respiratory Questionnaire (SGRQ) [4, 10]. Higher scores on the CAT test denote a more severe impact of COPD on a patient's life. No target score represents the best achievable outcome. Szczeklik A. and Gajewski P. suggest that scores $<10$ have a low impact, while results $\geq 10$ indicate a high severity of COPD symptoms requiring gradually more interventions [11].

The Distress Thermometer (DT) and Problem List (PL) is a an easy-to-understand single-item screening scale for distress. On this individual 11-point scale, patients rate their level of distress (0-10 with increasing distress). The DT is a brief, noninvasive, valid and acceptable alternative to longer psychometric instruments. The associated Problem List (PL) asks patients to respond to 36 items summarized into five categories: practical problems, family-related problems, emotional problems, spiritual/religious problems and physical problems. The PL aims to better define the nature of the individual patient's problems that may possibly be the cause of the reported distress (Fig. 2). The Distress Thermometer was first introduced by the American Cancer Society; in Poland, it was adapted by Jolanta Życińska, Ewa Wojtyna, Alicja Heyda and Anna Syska-Bielak [12, 13]. The Distress Thermometer and Problem List can be completed within 5 minutes and can be used to help reassure patients that their healthcare provider is interested in all aspects of their mind, body and spirit. Distress management screening helps to identify patients experiencing distress and the associated problems affecting that distress [14]. In Polish patients, a score of four or more on the Distress Thermometer has been suggested to be clinically significant distress, warranting further assessment for possible referral to psychological services [15]. This cutoff point has been widely validated against established measures of depression and anxiety. It is worth mentioning that the American interpretation is quite different, with the minimum level of significant distress set at five or more [16].

Participants. Over several months (between January 2018 October 2018), a total of 70 COPD patients were enrolled in this prospective study in the Department of Pulmonology, Oncology and Allergology at the Medical University in Lublin, Poland. All participants underwent spirometry and were classified into different COPD severity groups (A, B, C or D). The mean age was $69.6 \pm 9.05$ (range $47-90$ ) years. The general characteristics of the patients are shown in Table 1, and classification into COPD groups (according to GOLD standards) are depicted in Figure 3. All patients received the optimal treatment according to their GOLD classification. The criteria for inclusion in the study were: age over 40, diagnosis of COPD set by a pulmonologist, and willingness to participate in the study. The exclusion criteria were: current asthma, significant comorbidity (such as tuberculosis, ischemic heart disease or malignancy), alpha-1 antitrypsin deficiency.

Method. After history taking and physical examination, all patients were asked to complete the original questionnaire including the CAT score and the Distress Thermometer
BCREENING TOOLS FOR MEASURING DIGTRESS

Insiructions: First please circle the number $00-10)$ that best describes how much distress you have been experiencing in the past we ok including today.

\section{Extreme distress}

No distress:

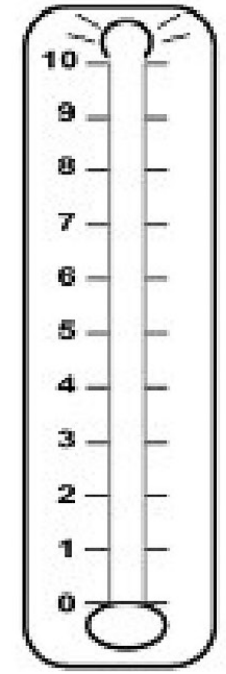

\begin{tabular}{|c|c|c|c|c|c|}
\hline \multicolumn{6}{|c|}{$\begin{array}{l}\text { Second please indieste if any of the followeing has been a } \\
\text { probiem for you in the past week including today. Be sure to } \\
\text { eheek ves or wo for taeh. }\end{array}$} \\
\hline \multirow{2}{*}{$\begin{array}{c}\text { YES } \\
\text { 口 }\end{array}$} & \multirow{2}{*}{$\begin{array}{l}\text { No } \\
\square\end{array}$} & \multirow{2}{*}{$\begin{array}{l}\text { Pinactical Problems } \\
\text { Chid care }\end{array}$} & \multirow{2}{*}{$\begin{array}{l}\text { YES } \\
\square\end{array}$} & \multicolumn{2}{|c|}{ MO Plyalcal Prablona } \\
\hline & & & & $\square$ & Appoarance \\
\hline$\square$ & $\square$ & Housing & 口 & $\square$ & Bathingldrassing \\
\hline$\square$ & $\square$ & Insurancelinancial & 口 & $\square$ & Breahing \\
\hline ㅁ & 口 & Transportation & 口 & 口 & Changes in urination \\
\hline \multirow[t]{3}{*}{$\square$} & 口 & Workisehoel & 口 & ㅁ & Consipation \\
\hline & & & $\square$ & $\square$ & Ciamtea \\
\hline & & EamiluProblems & $\square$ & $\square$ & Esting \\
\hline 口 & $\square$ & Dealing with children & $\square$ & $\square$ & Fatigur \\
\hline$\square$ & $\square$ & Dealing with partner & $\square$ & $\square$ & Feeling Swollen \\
\hline \multirow[t]{3}{*}{ 口 } & $\square$ & Abilky to have children & $\square$ & $\square$ & Favars \\
\hline & & & 口 & $\square$ & Getting a fround \\
\hline & & Emotianal Problama & $\bar{\square}$ & 口 & Indigestion \\
\hline$\square$ & 口 & Deprabsion & 口 & प & Memoryiconcentration \\
\hline ㅁ & 口 & Fears & $\overline{0}$ & $\bar{\square}$ & Mouth sares: \\
\hline ㅁ & $\square$ & Nervousness & $\bar{q}$ & $\bar{\square}$ & Nausea \\
\hline 口 & $\square$ & Sachess & 口 & $\square$ & Nose dryicongested \\
\hline$\square$ & $\square$ & Whry & a & $\bar{\square}$ & Pain \\
\hline \multirow[t]{2}{*}{$\square$} & $\square$ & Loss of interest in & 口 & $\vec{\square}$ & Senual \\
\hline & & 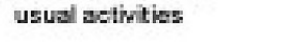 & 口 & $\square$ & skin dryituhy \\
\hline \multirow{2}{*}{$\square$} & & & 口 & ㅁ & slaep \\
\hline & D & 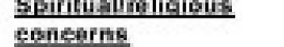 & $\square$ & $\square$ & Tingling in handsfleet \\
\hline
\end{tabular}

Other Probiems:

Figure 2. The Distress Thermometer and Problem List 
Table 1. General characteristics of the COPD patients

\begin{tabular}{lc}
\hline $\begin{array}{l}\text { COPD Patients Characteristics } \\
\mathbf{N}=\mathbf{7 0}\end{array}$ & Data \\
\hline Men/Women & $60 \% / 40 \%$ \\
\hline Age & $60.56-78.66$ years \\
\hline Smoking & $32.23 \pm 15.12$ years \\
\hline Weight & $73.04 \pm 15.18 \mathrm{~kg}$ \\
\hline COPD comorbidities & $90 \%$ of patients \\
\hline
\end{tabular}

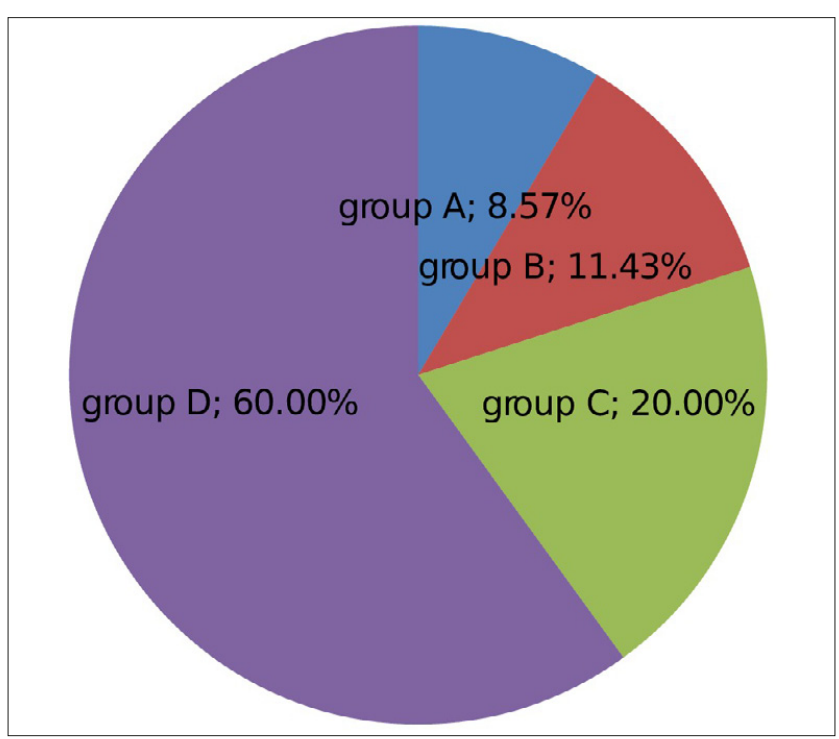

Figure 3. Characteristics of the patients according to GOLD COPD groups

and Problem List. The questionnaire was completed during a patient's hospitalization or while they were waiting for an appointment with their doctor. Patients were instructed on how to complete the scale. Most responders answered the questions without any doctor's help, but there were some patients who needed help in completing the questionnaire.

The total CAT score was calculated for each individual patient by summing-up the points for each variable. The CAT score ranges from $0-40$, and the CAT scores were classified into two groups: low $(<10)$ and high severity $(\geq 10)$ impact level of disease on health status. Descriptive analysis was carried out for the data from the feedback questionnaire containing the basic clinical data (e.g. age, gender, graded $A B C D$ assessment according to GOLD COPD 2019 guidelines), the CAT test and the Distress Thermometer.

Statistical analysis. MS Excel 2010 (Microsoft) was used to collect data and support the statistical analysis. Proper statistical analysis was performed using Statistica v.12.5 (StatSoft). A 5\% error of inference and an associated significance level of $p<0.05$ indicating the occurrence of statistically significant differences or dependencies were accepted. The mean value and the standard deviation were calculated for the quantitative data. In the statistical analysis, the Chi-Square dependence test was used to assess the relationship between the CAT score and the distress scale under study on the nominal and ordinal scale. This relationship was determined using Spearman's rank correlation. The Mann-Whitney U test was used to evaluate the difference between the two unrelated groups (to forecast further research).
Ethics. The study was approved by the Bioethics Committee of the Medical University in Lublin (No. KE-0254/218/2018) and all patients provided written informed consent. The work was carried out in accordance with the Code of Ethics of the World Medical Association.

\section{RESULTS}

The average distress level among participants was 4.09. On the PL scale, the most common problems were: breathing (94.29\%), nervousness (78.57\%), fatigue (75.71\%) and sleep (74.29\%), while the rarest problems among the COPD patients were connected with work/school and religious concerns. The average CAT score was 24.6 \pm 5.15 .

The initial hypothesis was confirmed: there was a correlation between CAT score and the result on the Distress Thermometer scale. There was a statistically significantly lower result on the Distress Thermometer in patients with a CAT test score below $10(\mathrm{~N}=6)$ compared with patients with a CAT test score of 10 and above $(\mathrm{N}=64 ; \mathrm{p}<0.001)$ (Tab. 2 and Fig. 4). Taking into account Spearman's rank correlation, a statistically significantly positive correlation between CAT scale scores and Distress Thermometer results was calculated $(r(68)=0.53 ; p<0.001)($ Tab. 3 and Fig. 5).

Table 2. Mann-Whitney $U$ test for CAT scores and Distress Thermometer results

\begin{tabular}{lccccccc}
\hline \multicolumn{7}{c}{ Mann-Whitney U test } \\
\hline & $\begin{array}{l}\text { Sum. } \\
\text { rang } \\
\text { CAT } \geq 10\end{array}$ & $\begin{array}{c}\text { Sum. } \\
\text { rang } \\
\text { CAT }<10\end{array}$ & U & Z & p & $\begin{array}{c}\text { N } \\
\text { import. } \\
\text { CAT } \geq 10\end{array}$ & $\begin{array}{c}\text { N } \\
\text { import. } \\
\text { CAT }<10\end{array}$ \\
\hline $\begin{array}{l}\text { Distress } \\
\text { Thermometer }\end{array}$ & 2434,00 & 51,00 & 30,00 & 3,39 & $<0,01$ & 64 & 6 \\
\hline
\end{tabular}

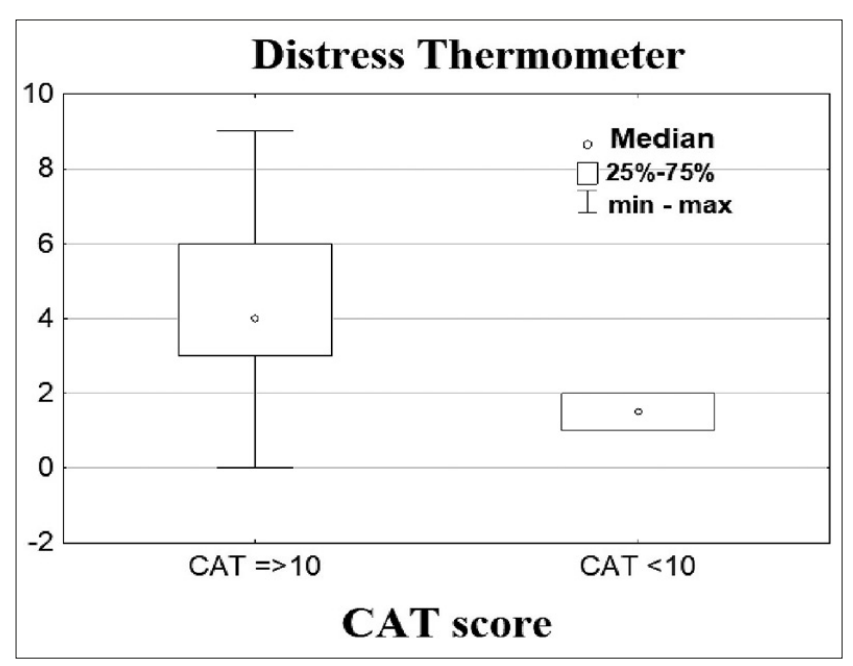

Figure 4. Relationship between CAT scores and Distress Thermometer results

Table 3. Spearman's rank correlation between CAT scale and Distress Thermometer scores

\begin{tabular}{lcccc}
\hline & \multicolumn{4}{c}{$\begin{array}{c}\text { Spearman's rank correlation } \\
\text { correlation coefficients are important }(\mathrm{p}<.05000)\end{array}$} \\
\cline { 2 - 5 } & $\begin{array}{c}\mathrm{N} \\
\text { Import. }\end{array}$ & $\begin{array}{c}\mathrm{R} \\
\text { Spearman }\end{array}$ & $\mathrm{t}(\mathrm{N}-2)$ & $\mathrm{p}$ \\
\hline $\begin{array}{l}\text { CAT SCALE \& DISTRESS } \\
\text { THERMOMETER }\end{array}$ & 70 & 0.528492 & 5.133535 & 0.000003
\end{tabular}




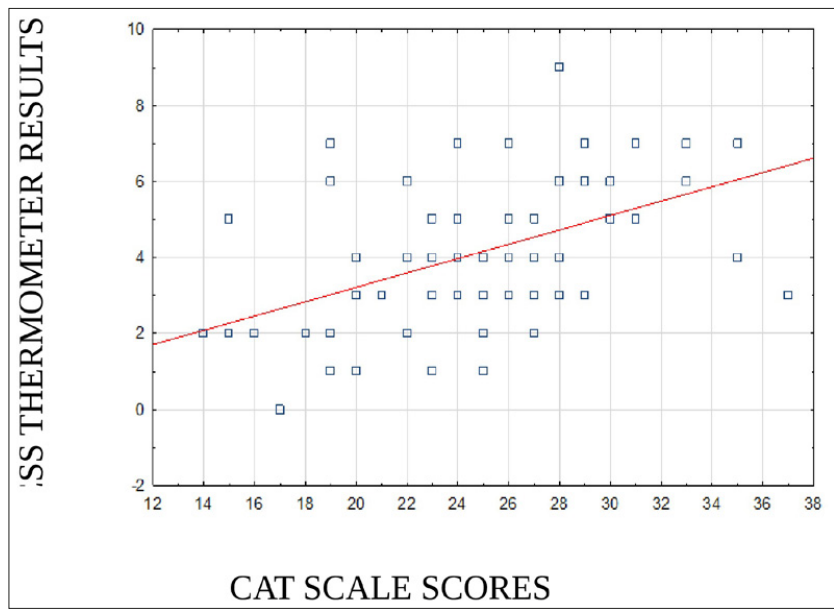

Figure 5. Scattering diagram: Distress Thermometer results versus CAT scale scores

\section{DISCUSSION}

The prevalence of COPD is expected to increase over the next 30 years, and by 2030, there might be over 4.5 million deaths annually from COPD and related comorbidities. Concomitant chronic diseases, e.g. anxiety and depression, are often connected with a poor prognosis $[17,18]$. Distress is an important symptom that may impact the quality of life of patients with COPD. Therefore, research into psychological intervention methods for COPD patients plays an important role in improving prognosis $[19,20]$.The clinical manifestations of COPD include dyspnea, productive cough and loss of pulmonary function, seriously affecting the patients' quality of life. There are many health status questionnaires used in COPD, and one of them is the CAT test, which is a simple and clear measurement of disease-specific quality of life. The Distress Thermometer and Problem List, however, is used to quantify negative emotional experience (distress) and identify important sources of distress $[21,22,23]$.

The presented study proved that health status decline evaluated by CAT score is distress measured by the Distress Thermometer: patients with COPD and higher CAT scores showed the highest level of distress. These data suggest that the CAT score and the result on the Distress Thermometer are compatible with COPD severity levels. Presented findings confirm that COPD severity assessed by the CAT score can be directly related to identifying biopsychosocial sources of distress by the Distress Thermometer. On the other hand, the CAT questionnaire can be employed as a predictor of patients who might require specialized psychological services.

The ability to compare the results with other studies using multivariate analysis is limited because of differences in statistical methods. However, the influence of distress and anxiety on health outcomes in COPD and the impact of CAT scores on COPD status have been well studied by researchers including Panagioti et al., Eisner et al., and Jing et al., but measuring the psychological state in COPD patients using the Distress Thermometer and Problem List is quite innovative $[24,25,26]$. To-date, validation of the Distress Thermometer and Problem List has been discussed mostly among oncological patients, but not among patients with COPD, which confirm the studies of Iskandarsyah et al., Hughes et al. and Ryan et al. [27, 28, 29].
The current findings demonstrate the need for psychological and social support, not only for oncological patients $[30,31$, $32,33,34]$, but also people suffering from COPD or other pneumonological morbidities [35]. The DT is a highly useful screening tool, but it is not a stand-alone diagnostic test. Consequently, doctors and other healthcare providers should utilize some psychological skills to help their patients and provide them with appropriate care [36].

The strength of this study is its innovative character describing the relationship between health status questionnaires such as CAT and psychological scales such as the Distress Thermometer. However, there are some limitations to this study that must be considered in future research. The relationship between distress and particular items on the CAT test, or the relation of the CAT to particular sections from the list of problems, were not systematically examined. However, such an analysis could result in a somewhat different interpretations of the CAT test, which previously has always been considered in the scientific literature as a whole eight-item measure of health impairment status in COPD. This gap in publications investigating particular CAT items indicates the need for further research.

\section{CONCLUSIONS}

The study supports the hypothesis that there is a correlation between health status questionnaires such as CAT and psychological scales such as the Distress Thermometer. The research advances new ideas in the psychological care of patients with COPD, which can provide a reference for clinicians. This research proves that every patient with COPD should be evaluated not only by CAT tests but also by scales measuring a psychological spectrum, such as the discussed Distress Thermometer. More studies are needed to ascertain the value of the correlation between CAT scores and the results on the Distress Thermometer.

\section{REFERENCES}

1. Global Initiative for Chronic Obstructive Lung Disease. Global strategy for the diagnosis, management, and prevention of chronic obstructive pulmonarydisease. https://goldcopd.org/wp-content/uploads/2017/11/ GOLD-2018-v6.0-FINALrevised-20-Nov_WMS.pdf (access: 2018.11.13)

2. Kim KU, Park HK, Jung HY, et al. Association of depression with disease severity inpatients with chronic obstructive pulmonary disease. Lung. 2014; 192: 243. doi:10.1007/s00408-013-9547-4.

3. Montserrat-Capdevila J, Godoy P, Marsal JR, et al. Overview of the Impact ofDepression and Anxiety in Chronic Obstructive Pulmonary Disease. Lung 2017; 195: 77. doi: 10.1007/s00408-016-9966-0.

4. Jones PW, Harding G, Berry P, et al. Development and first validation of the COPDAssessment Test. Eur Respir J. 2009; 34: 648. doi: 10.1183/09031936.00102509

5. NCCN practice guidelines for the management of psychosocial distress. National Comprehensive Cancer Network. Oncology (Williston Park). 1999 May; 13(5A): 113-47.

6. Grassi L, Sabato S, Rossi E, et al. Affective syndromes and their screening in cancer patients with early and stable disease: Italian ICD-10 data and performance of the Distress Thermometer from the Southern European Psycho-Oncology Study (SEPOS). J Affect Disord. 2009; 114(1-3): 193-9.

7. Śliwiński P, Górecka D, Jassem E, Pierzchała W. Polish Respiratory Society Guidelines for Chronic Obstructive Pulmonary Disease. Pneumonol Alergol Pol. 2014; 82; 3: 227-263.

8. Meguro M, Barley EA, Spencer S, et al. Development and validation of an improved, COPD-specific version of the St. George Respiratory Questionnaire. Chest. 2007; 132: 456-463. doi:10.1378/chest.06-0702. 
9. Eisner MD, Blanc PD, Yelin EH, et al. Influence of anxiety on health outcomes in COPD. Thorax. 2010; 65(3): 229-34. doi: 10.1136/ thx.2009.126201.

10. Jones PW, Tabberer M, Chen WH. Creating scenarios of the impact of COPD and their relationship to COPD Assessment Test $\left(\mathrm{CAT}^{\mathrm{TM}}\right)$ scores. BMC Pulm Med. 2011; 11: 42. doi: 10.1186/1471-2466-11-42.

11. Gajewski P, Szczeklik A. Interna Szczeklika. Kraków; 2018.

12. Życińska J, et al. Polska adaptacja skali DistressThermometer i Problem List. Badania walidacyjne wśród pacjentów onkologicznych. X Ogólnopolska Konferencja Psychoonkologiczna. 11-12 września 2009, Władysławowo. Abstrakt wystąpienia. Access mode: http:// www.ptpo.org.pl/index/index.php?option=com_content\&task=view \&id=151 (access: 2019.01.14)

13. Gil F, Grassi L, Travado L, Tomamichel M, Gonzalez JR. Use of distress and depressionthermometers to measure psychosocial morbidity among southern European cancerpatients. Supportive Care In Cancer: Official Journal Of The Multinational Association Of Supportive Care In Cancer. 2005; 13: 600-606. doi: 10.1007/s00520-005-0780-0.

14. Lynch J, Goodhart F, Saunders Y, O'Connor SJ. Screening for psychological distress inpatients with lung cancer: results of a clinical audit evaluating the use of the patientDistress Thermometer. Support Care Cancer. 2010; 19(2): 193-202. doi: 10.1007/s00520-014-2471-1.

15. Holland JC, Bultz BD. National Comprehensive Cancer Network (NCCN). The NCCNguideline for distress management: a case for making distress the sixth vital sign. J Natl Compr Canc Netw. 2007; 5: $3-7$.

16. Omachi TA, Katz PP, Yelin EH, Gregorich SE, Iribarren C, Blanc PD, et al. Depressionand health-related quality of life in chronic obstructive pulmonary disease. Am JMed. 2009; 122(8): 778 e9-15. doi: 10.1016/j. amjmed.2009.01.036

17. The NCCN. Distress Management (Version 1.2008) National Comprehensive Cancer Network, Inc. 2007. http://www.nccn.org (access: 2019.01.14)

18. Hill K, Geist R, Goldstein RS, Lacasse Y. Anxiety and depression in end-stageCOPD. EurRespir J. 2008; 31(3): 667-77. doi: 10.1183/09031936.00125707.

19. Kim KU, Park HK, Jung HY, et al. Association of depression with disease severity inpatients with chronic obstructive pulmonary disease. Lung 2014; 192: 243.

20. Ghobadi H, Ahari SS, Kameli A, Lari SM. The Relationship between COPD AssessmentTest (CAT) Scores and Severity of Airflow Obstruction in Stable COPD Patients, Tanaffos. 2012; 11(2): 22-26.

21. Shim EJ, Shin YW, Jeon HJ, Hahm BJ. Distress and its correlates in Koreancancer patients: pilot use of the distress thermometer and the problem list. Psycho-Oncology 2008; 17(6): 548-555. doi: 10.1002/ pon.1275.

22. Clover K, Carter G, Mackinnon A, Adams C. Is my patient suffering clinicallysignificant emotional distress? Demonstration of a probabilities approach to evaluatingalgorithms for screening for distress. Support Care Cancer. 2009; 17: 1455-1462. doi:10.1007/s00520-009-0606-6

23. Lim HA, Mahendran R, Chua J, et al. The Distress Thermometer as an ultra-short screening tool: a first validation study for mixed-cancer outpatients in Singapore. Compr Psychiatry 2014; 55: 1055.

24. Panagioti M, Charlotte Scott C, Blakemore A, Coventry P. Overview of the prevalence,impact, and management of depression and anxiety in chronic obstructive pulmonarydisease. Int J Chron Obstruct Pulmon Dis. 2014; 9: 1289-1306. doi:10.2147/COPD.S72073

25. Eisner M, Blanc P, Yelin E, Katz P, Sanchez G, Iribarren C, Omachi T. The influence of anxiety on health outcomes in COPD. Thorax. 2010 Mar; 65(3): 229-234. doi:10.1136/thx.2009.126201

26. Jing L, Guangju M, Yi M, Xia Z, Dongmei C, Mengting C. Influence of COPDAssessment Text (CAT) evaluation and rehabilitation education guidance on therespiratory and motor functions of COPD patients, Open Med (Wars). 2015; 10(1): 394-398.

27. Iskandarsyah A, Klerk C, Suardi D, Soemitro M, Sadarjoen S. The Distress Thermometerand Its Validity: A First Psychometric Study in Indonesian Women with Breast Cancer. PLoS One. 2013; 8(2): e56353. doi: 10.1371/journal.pone.0056353

28. Hughes K, Sargeant H, Hawkes A. Acceptability of the Distress Thermometer andProblem List to community-based telephone cancer helpline operators, and to cancerpatients and carers.BMC Cancer. 2011; 11: 46. doi: 10.1186/1471-2407-11-46

29. Ryan H, Schofield P, Cockburn J, et.al. How to recognize and manage psychologicaldistress in cancer patients. Eur J Cancer Care (Engl). 2005 Mar; 14(1): 7-15. doi:10.1111/j.1365-2354.2005.00482.x

30. Donovan KA, Grassi L, McGinty HL, Jacobsen PB. Validation of the distress thermometer worldwide: state of the science. Psychooncology 2014; $23: 241$.

31. Chiou YJ, Lee CY, Li SH, et al. Screening for Psychologic Distress in Taiwanese Cancer Inpatients Using the National Comprehensive Cancer Network Distress Thermometer: The Effects of Patients' Sex and Chemotherapy Experience. Psychosomatics 2017; 58: 496.

32. Bidstrup PE, Mertz BG, Dalton SO, et al. Accuracy of the Danish version of the 'distress thermometer'. Psychooncology 2012; 21: 436.

33. Tang LL, Zhang YN, Pang Y, et al. Validation and reliability of distress thermometer in chinese cancer patients. Chin J Cancer Res. 2011; 23: 54.

34. Chambers SK, Zajdlewicz L, Youlden DR, et al. The validity of the distress thermometer in prostate cancer populations. Psychooncology 2014; 23: 195.

35. San Giorgi MR, Aaltonen LM, Rihkanen $\mathrm{H}$, et al. Validation of the Distress Thermometer and Problem List in Patients with Recurrent Respiratory Papillomatosis. Otolaryngol Head Neck Surg. 2017; 156: 180.

36. Ma X, Zhang J, Zhong W, et al. The diagnostic role of a short screening tool--the distress thermometer: a meta-analysis. Support Care Cancer $2014 ; 22: 1741$. 